\title{
Robust Wide Area Controller Design with DFIG-Fractional Order PID for Inter-Area Oscillations Damping
}

\author{
Cheng Liu ${ }^{1} *$, Guowei $\mathrm{Cai}^{1}$ and Mingna Zhang ${ }^{2}$ \\ ${ }^{1}$ School of Electrical Engineering, \\ Northeast Dianli University, Jilin, China \\ ${ }^{2}$ State Grid Corporation of China, \\ Jilin Power Supply Company, Jilin, Jilin Province, China \\ Corresponding E-mail:05dylc@163.com
}

\begin{abstract}
At present, the double-fed induction generator (DFIG) has been used in power system widely. Containing the characteristics of strong nonlinearity and model uncertainty of interconnected power grid with doubly-fed wind power generation system. In this paper, a simple fractional order PID wide-area damping controller is designed, in order to enhance damping control of the interconnected power grid containing doubly-fed wind turbine, and to restrain power oscillation. The additional control can be add into DFIG to damp power oscillation and it doesn't add additional equipment. The remote-signal is introduced into wide area damping controller (WADC) of DFIG, in order to reduce the power oscillation of interconnected power system. For designing damp controller, firstly the stochastic subspace identification technique (SSI) was used to derive low frequency oscillations parameters for interconnected power system from responses measured by wide area measurement systems (WAMS). Then novel robust wide area damping control approach for reducing power oscillation using the Fractional order PID (FOPID) method is presented. This method has good dynamic characteristics under different case, and has the advantages of quick response, strong adaptability. The effectiveness and robustness of proposed WADC of DFIG have been used to be verified by detailed examples inspired by the 4-generator 2-area and 7-generator 4-area test system under different disturbance cases.
\end{abstract}

Keywords: Double-fed induction generator, inter-area oscillation, stochastic subspace identification (SSI), fractional order PID, wide area damping controller (WADC)

\section{Introduction}

Inter-area oscillation has severe threaten for stable of interconnected power grids [1,2]. Local-signal-based power system stabilizer (LPSS) has been used to damp local oscillation modes, while it has limited effectiveness to inter-area mode [3]. Now, advanced schemes used in power system have been influenced by Wide Area Measurement Systems (WAMS) [4-7]. With development of WAMS,inter-area oscillation modes have been suppressed by remote-signals-based PSS[7].

The inter-area oscillation parameter are identified by Prony [8]. It provides a basis for damping control. PSS could be designed on $\mathrm{H} \infty$ [9] and linear matrix inequality (LMI) $[10,11]$, so as to improve damp of power system. Above-mentioned methods, the practicability of wide area damping controller (WADC) would be weaken by complexity of method.

In recent years, the application of flexible AC transmission systems (FACTS) device is becoming a more practical approach [12-13]. But it increases the additional equipment. Now, the double-fed induction generator (DFIG) has been used in power system widely. 
If DFIG can be designed with wide area damping control and used in damping inter-area oscillation, it will not increase additional equipment and achieve better effect.

At present, there are some types of damping control based on DFIG[14-16]. In [17], through an adequate selection of input-output signal, wind plant can be effectively used to provide electromechanical oscillations for damping. In [18], non-linear control of DFIG is used to damp oscillations. In [19], it proposes a robust control scheme of power oscillation damping (POD) for a DFIG-based wind turbine using a specified structure mixed $\mathrm{H}_{2} / \mathrm{H}_{\infty}$ control. But these methods are more complicated and difficult to realize.

In recent years, fractional order PID(FOPID) has been applied in power systems. Its characteristic is high control precision and easy to implement[20-23]. It is used in automatic generation control(AGC)[20],automatic regulator voltage(AVR)[21],load frequency control(LFC) [22], et al. But it is seldom used to damping control of DFIG. In this article, wide-area damping controller of DFIG is designed on FOPID, so as to suppress inter-area oscillation of power grid with wind power. The simulation results show that transient response, robustness and disturbance rejection of the designed FOPID controller are better than those are without DFIG-FOPID controller.

The rest part of article is organized as follows. The principle and design of FOPID are given in Section 2. The adaptive WADC of remote-signal-based DFIG-FOPID is proposed and designed in Section 3. Section 4 shows the stochastic subspace identification (SSI) is used to derive low frequency oscillations parameters, and inter-area oscillation modes are identified. Section 5 describes proposed WADC of DFIG and design flow. In Section 6, the effectiveness and robustness presented adaptive WADC for damping inter-area oscillation have been validated by simulations on different cases. Finally, the conclusions are made in Section 7.

\section{The Principle and Design of FOPID}

\subsection{Definition of Fractional Integral}

A FOPID have five characteristics parameters: proportional gain, integral gain, differential gain, integral order, differential order. The main idea of fractional integral is creating a factor $D$. The order $v$ of $D$ mustn't be integer, namely concept of differentiation (when $v$ is positive) and integration (when $v$ is negative) is promoted.

The expansion definition of the integer-order differential is proposed in [24] :

$D_{x}^{-n} f(x)=\int_{c}^{x} \frac{(x-t)^{n-1}}{(n-1) !} f(t) d t \quad n \in N$

The general definition of function operator $D$ is in the following:

$$
D_{x}^{v} f(x)=\left\{\begin{array}{c}
\int_{c}^{x} \frac{(x-t)^{-v-1}}{\Gamma(-v)} f(t) d t, \quad \text { if } v<0 \\
f(x), \text { if } v=0 \\
D^{n}\left[D_{x}^{\nu-n} f(s)\right], \text { if } v>0
\end{array}\right.
$$

where ${ }^{\Gamma()}$ is gamma function, ${ }^{n=\min }\{K \in N: k>v\}$.

The (3) gives the Laplace transform of $D$,

$$
L\left[D_{x}^{v}\right]=\left\{\begin{array}{c}
s^{v} F(s), \text { if } v \leq 0 ; \\
s^{v} F(s)-\sum_{k=0}^{n-1} s^{k} D_{x}^{v-\kappa-1} f(0), i f n-1<v<n \in N
\end{array}\right.
$$

If initial conditions is assumed, the dynamic behavior of system can be described with differential equations and fractional differentiation, then transfer function of the system will be fractional order $s$ [24-25]. 


\subsection{Integer Approximation}

For the transfer function equipped with fractional order $s$, the common method is to use a integral order transfer function to approximate. The integer order transfer function contains infinite number of poles and zeros, so as to approximate a fractional order transfer function. However, we can get an integer transfer function approximation with fractional transfer function, and it include a limited number of poles and zeros.

A well-known approximation was raised by Oustaloup [25]. The (4) gives the approximate transfer function,

$s^{v} \approx k \prod_{n=1}^{N} \frac{1+\left(s / w_{z, n}\right)}{1+\left(s / w_{p, n}\right)}$,

In the frequency domain within the range ${ }^{\left[w_{10}, w_{\mathrm{in}}\right]}$, the approximation is feasible. Adjusting the gain k, when both sides of the (4) at a frequency of $1 \mathrm{rad} / \mathrm{s}$ as a unity gain.

Firstly the number of poles and zeros are selected well, the desired performance of approximate transfer function depends on order $N$. Low-level $N$ will approximate simplified, but it could lead to fluctuations in gain and phase. By increasing the order of $N$ to avoid such fluctuations. However, the amount of computation for approximating will increase.

If $^{|v|>1}$, this approximation is not ideal. So fractional order $s$ is usually broken down into following:

$s^{v}=s^{n} s^{\delta}$.

where ${ }^{v=n+\delta, n \in \square, \delta \in[0,1]}$, then only the $s^{\delta}$ needs to be approximated.

\subsection{FOPID Controller}

Differential equation of the fractional order controller for $P I^{\lambda} D^{\mu}$ is as follows: $u(t)=k_{p} e(t)+k_{i} D_{t}^{-\lambda} e(t)+k_{d} D_{t}^{\delta} e(t)$

As shown in (7), the transfer function of FOPID can be gotten by Laplasse transform,

$G_{c}(s)=k_{p}+k_{i} s^{-\lambda}+k_{d} s^{\delta}$

When FOPID controller is designed, five parameters $k_{i}, k_{p}, k_{d}, v_{i}=-\lambda, v_{d}=\delta$ needed to be considered. They are not necessary integer. The performance of conventional PID controller is promoted by fractional order controller.

\section{Design of WADC for Remote-Signal-Based DFIG-FOPID}

\subsection{The Mathematical Model of DFIG}

The DFIG adding a FOPID in inverter control model (DF1G-FOPID) in this paper, namely the DFIG-FOPID control module which takes the electromagnetic power as input signal and an additional voltage $u_{F O P I D}$ as the output signal. Using the inverter control of wind generator to make the output related to system oscillation damping oscillation, so as to improve the system damping effect and the ability to suppress low frequency oscillation. Electromagnetic torque and electromagnetic power are as follows respectively:

$T_{e}=L_{m}\left(i_{s q} i_{r d}-i_{s d} i_{r q}\right)$

$P_{e}=-\frac{w_{r} L_{m}}{L_{s}} \psi_{s} i_{r q}$ 
where $L_{m}$ is mutual inductance of the rotor and stator ; $i_{s q}, i_{s d}, i_{r d}, i_{r q}$ is stator and rotor current component in the $d-q$ axis respectively; $\omega_{r}$ is the angular velocity of the rotor; ${ }^{L_{s}}$ is stator inductance; $\psi_{s}$ is stator flux vector.

As shown in (9), under the condition of constant the stator flux linkage amplitude $\psi_{s}$, electromagnetic power output of DFIG can be controlled by the rotor current $q$ axis component ${ }^{i_{r q}}$ independently. And the relationship between the rotor current and the rotor voltage is as follows:

$$
\begin{aligned}
& u_{r d}=R_{r} i_{r d}+\sigma L_{r} d^{i_{r d}} / d t-\omega_{s} \sigma L_{r} i_{r q} \\
& u_{r d}=R_{r} i_{r q}+\sigma L_{r} d^{i_{r q}} / d t+\omega s\left(L_{m} \psi_{s} / L_{s}+\sigma L_{r} i_{r d}\right)
\end{aligned}
$$

where $u_{r d}, u_{r q}$ is rotor voltage component in $d$-q axis respectively; $R_{r}$ is rotor resistance; $\sigma$ is leakage resistance factor; ${ }^{L_{r}}$ is the inductance of the rotor; ${ }^{\omega_{s}}$ is the angular velocity of the stator.

The disturbance compensation is introduced into, let:

$e_{r d}=-\omega_{s} \sigma L_{r} i_{r q}$

$e_{r q}=\omega_{s}\left(L_{m} \psi_{s} / L_{s}+\sigma L_{r} i_{r d}\right)$

Then:
$u_{r d}=R_{r} i_{r d}+\sigma L d^{i_{r d}} / d t+e_{r d}$
$u_{r q}=R_{r} i_{r q}+\sigma L d^{2} / d t$

After compensating disturbance (Figure 1), ${ }_{r d}$ and ${ }^{u_{r q}}$ realize the rotor current $i_{r d}$ and $i_{r q}$ decoupling control. At the same time, the voltage to current equation is first-order inertia link, a good current control characteristic can be obtained.

\subsection{Design of Adaptive WADC}

When power systems connected with large-scale wind farms, the interaction between wind farms and large power grids will be very complicated. There are some coupling relationship between exists electromagnetic oscillations of DFIG power output and power oscillation of interconnected power system areas. Its active power and reactive power can be controlled independently through the inverter control for DFIG unlike conventional synchronous generators.

In this paper, a WADC for DFIG is designed based on WAMS signal (regional synchronous generator rotor speed difference $\Delta \omega$ ). The wide area damping control signal is attached to active power control loop of DFIG, using the system state parameters to adjust the active input of DFIG to improve the ability of low frequency oscillation suppressing for large-scale wind farm.

It takes the rotor speed difference $\Delta \omega$ as input signal and an additional voltage $u_{F O P I D}$ as the output signal. The output signal is added in the rotor voltage $u_{r d}$ of the power control for DFIG, so as to produce additional electromagnetic torque with the phase same as speed variation $\Delta \omega$, resulting additional damping torque. The structure of WADC is shown in Figure1. 


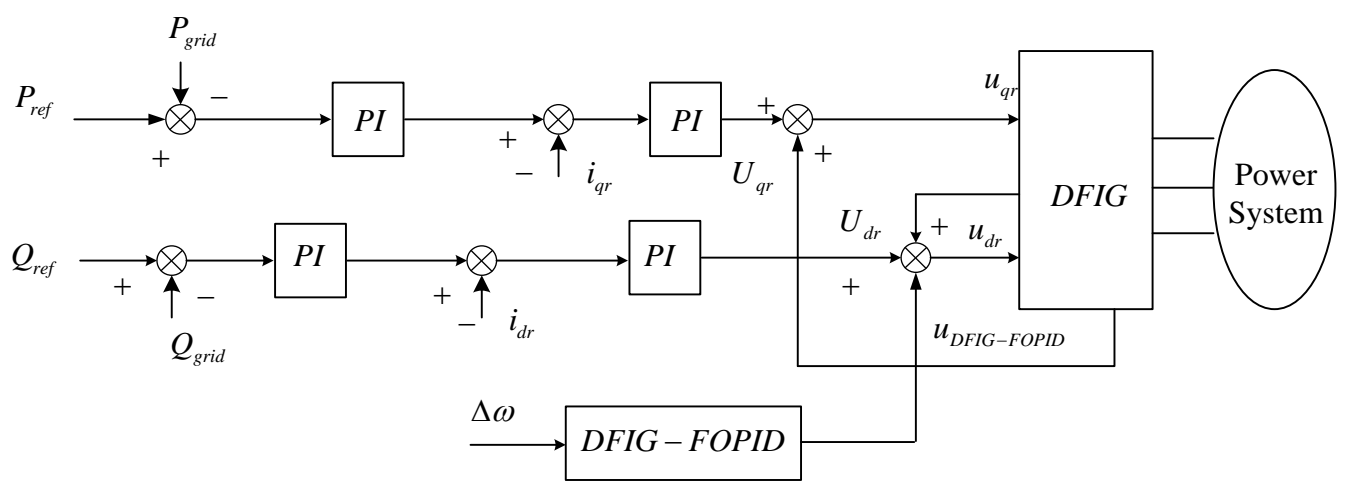

Figure 1. Diagram of Additional Damping Control Structure

For power system, the linearized state-space model can be shown in the following:

$\dot{X}=\tilde{A} \boldsymbol{X}+\tilde{\mathrm{B}} \boldsymbol{u}$

$\boldsymbol{Y}=\tilde{\boldsymbol{C}} \boldsymbol{X}$

$\tilde{\boldsymbol{A}} \in \mathfrak{R}^{n \times n}, \tilde{\boldsymbol{B}} \in \mathfrak{R}^{n \times m}, \tilde{\boldsymbol{C}} \in \mathfrak{R}^{p \times n}$

The results of eigenvalue analysis can be gotten from (13).

When left eigenvectors $e_{i}$ and right eigenvectors $f_{i}$ can be gotten, the residue of mode $i$ is expressed as follows:

$R_{i}=\tilde{C} e_{i} f_{i}^{T} \tilde{B}$

Transfer function of system can be shown in the following:

$G(s)=\sum_{i=1}^{n} \frac{R_{i}}{s-\lambda_{i}}$

where $\lambda_{i}$ is system eigenvalue.

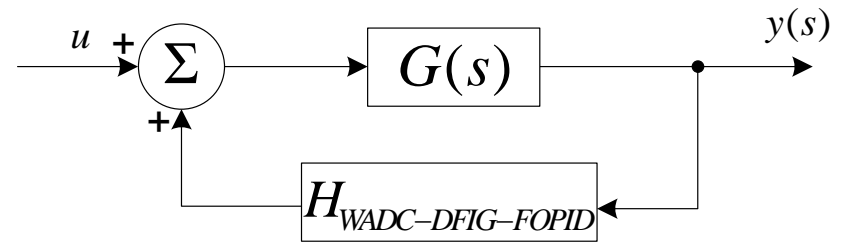

Figure 2. The Simplified Closed-loop Control Structure with a DFIG-FOPID in the System

As shown in Figure 2, DFIG-FOPID is added to damp oscillation mode. The new transfer function is shown as follows:

$$
1+H_{W A D C_{i}}(s) G(s)=1+H_{W A D C_{i}}(s) \sum_{i=1}^{n} \frac{R_{i}}{s-\lambda_{i}}=0
$$

If $\lambda_{i}$ changes very little, the change ${ }^{\lambda_{i}}$ is approximated as (17): $\Delta \lambda_{i} \approx H_{\mathrm{WADC}_{i}}\left(\lambda_{i}\right) R_{i}$

$\Delta \lambda_{i}$ shall be a negative real number. So ${ }^{\lambda_{i}}$ should be left on complex plane. Because the purpose of the $W A D C_{i}$ is damp oscillation mode $i$. 


\section{Parameter Identification based on Stochastic Subspace Identification}

The state space model and important inter-area oscillation modes are obtained from the measuring signals, so as to design the WADC. In this paper, SSI [26] is adopted to estimate state space model and derive low frequency oscillations parameters of power system online using measured signals to make sure whether to use DFIG-WADC is used to suppress inter-area oscillation.

\subsection{Estimation of State Space Model}

The discrete time invariant system can be shown in the following [26]:

$$
\begin{aligned}
x(k+1) & =A_{d} x(k)+B u(k) \\
y(k) & =C x(k)+D u(k)
\end{aligned}
$$

where vectors $u(k) \in \mathfrak{R}^{m}, y(k) \in \mathfrak{R}^{l}$ are measured at $k$ time; $x(k)$ is state vector at $k$ time; $A_{d}, B, C$, and $D$ are different dimensions matrices.

If the input $u(k)$ and output $y(k)$ are given, and order $N_{\text {order }}$ of uncertain system are determined, the matrices $\left(A_{d}, B, C, D\right)$ can be determined.

The subspace state space system identification (N4SID) [27] is adopted to determine state space model of system from impulse responses due to N4SID algorithm is noniterative, with no nonlinear optimization part involved.

\subsection{Mode Shape Identification and Modal Analysis of Power System}

The matrix $A_{d}$ can be shown in the following:

$$
\boldsymbol{A}_{\mathrm{d}}=\boldsymbol{\Psi}\left[\begin{array}{llll}
\eta_{1} & & & \\
& \eta_{2} & & \\
& & \ddots & \\
& & & \eta_{N}
\end{array}\right] \boldsymbol{\Psi}^{-1}
$$

where $\eta_{i}$ is the eigenvalue, ${ }^{i=1,2, \cdots N}, \Psi$ is eigenvector matrix. Eigenvalue $\lambda_{i}$ is obtained from $\eta_{i}$, and it is shown in the following [26]:

$\lambda_{i}=\frac{\ln \left(\eta_{i}\right)}{t_{s}}=a_{i}+j b_{i}$

Then modal parameters can be gotten in (21):

$f_{i}=\sqrt{a_{i}^{2}+b_{i}^{2}} / 2 \pi$

$\zeta_{i}=-a_{i} / \sqrt{a_{i}^{2}+b_{i}^{2}}$

where $\zeta_{i}$ is damping ratio, and $f_{i}$ is oscillation frequency. The oscillation mode shape matrix $\Phi$ is obtained in the following [26]:

$$
\Phi=C \Psi
$$

\section{Adaptive WADC Scheme and Design Flow for DFIG-FOPID}

The proposed WADC scheme with SSI identification and DFIG-FOPID is shown in Figure 3. Though PMU, the generator power deviation signals measured by PMU equipped generators between different areas are transmitted to WADC center. The local oscillation modes can be improved based on LPSS, the WADC is used to reduce inter- 
area oscillations. The principle of suppressing oscillations:(1) inter-area oscillation modes are identified online using SSI; (2) As to insufficient damping inter-area oscillation mode, the input and parameters of the WADC will be derived and tuned in order to improve damping of system; (3) the WADC-DFIG will suppress inter-area oscillations.

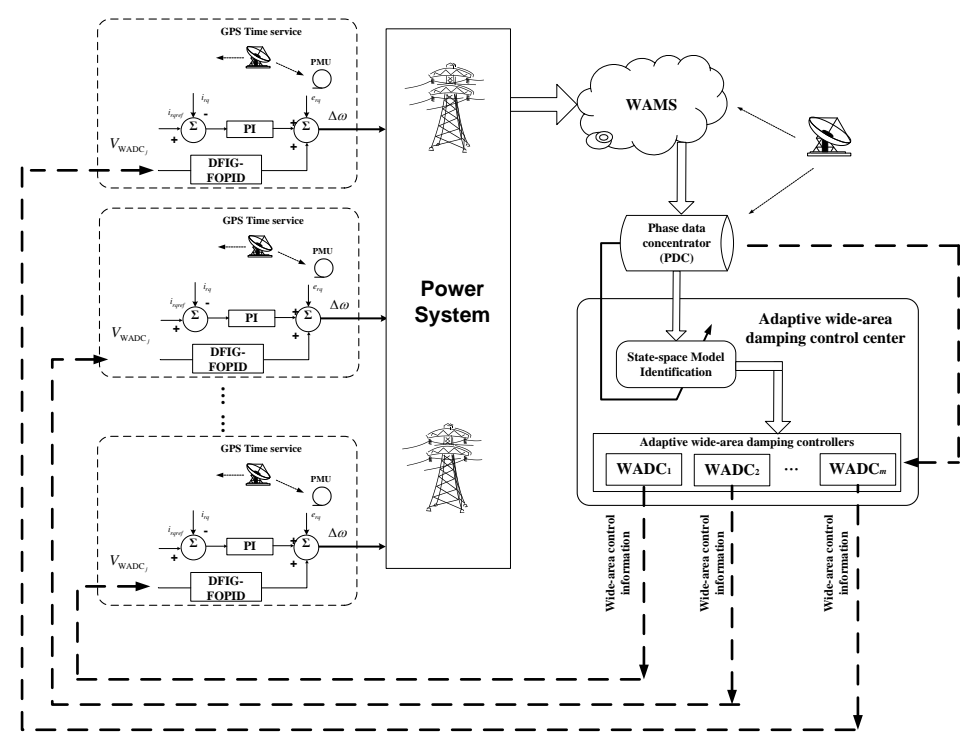

Figure 3. Adaptive WADC Scheme with DFIG-FOPID

The flow chart of the proposed WADC scheme is shown in Figure 4, which contains SSI algorithm, and WADC with DFIG-FOPID described in previous sections. The major design steps are in the following.

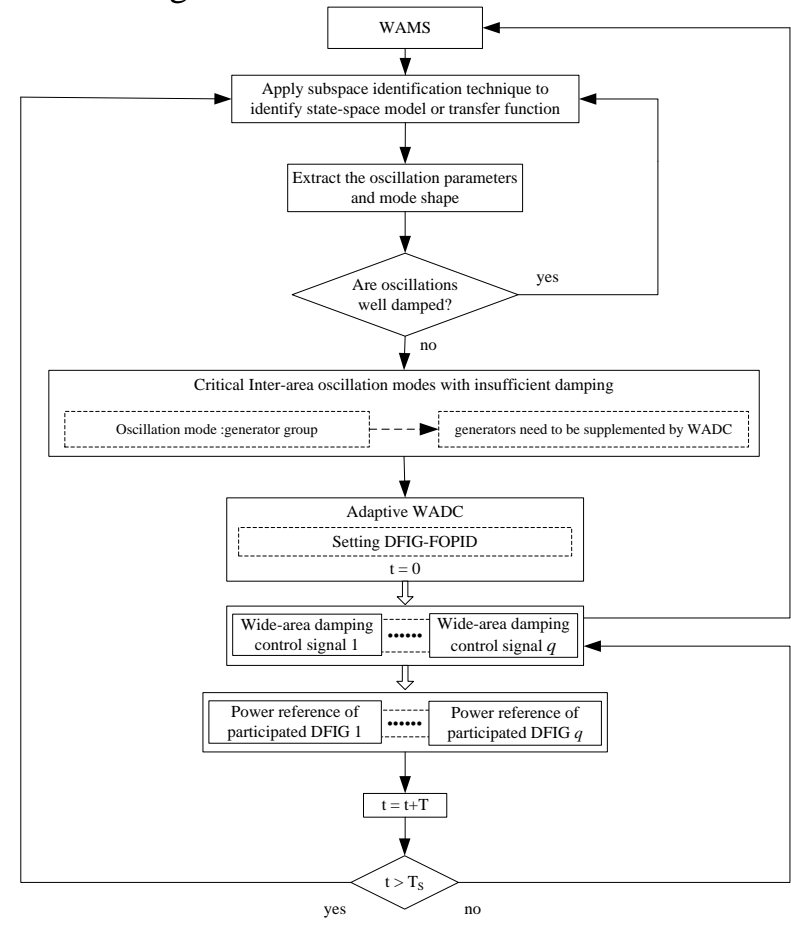

Figure 4. Flow Chart of Proposed DFIG Adaptive WADC Scheme

Step 1: The state-space model and oscillation parameters of the system are identified by SSI through WAMS data collected. 
Step 2: $\quad$ Inter-area oscillation modes are identified.

Step 3: If there is low damping inter-area oscillations, adaptive WADC is activated; otherwise, return to Step 1.

Step 4: The important smallest damping ratio inter-area oscillation modes is determined.

Step 5: $\quad$ Adaptive WADC for DFIG-FOPID is constructed and $\mathrm{t}=0$ is set.

Step 6: The signal time is measured and wide area control signal $V_{\mathrm{WADC}}$ is fed to the DFIG in order to damp targeted inter-area oscillation mode.

Step 7: $\quad$ Time-step $T_{s}$ is added and go back to Step 5 until next cycle.

Step 8: $\quad$ Go back to Step 1 to start a new cycle of WADC control.

\section{Simulation Studies}

CASE 1:As shown in Figure 5, the four-generator two-area system was selected for evaluating performance of the proposed adaptive WADC scheme based on FOPID. The data of this system can be obtained in [1]. The system contains 2 areas, namely, Area 1 (G1-G2), and Area 2 (G3-G4). LPSSs are equipped in G1. A DFIG wind farm is accessed to power system in AREA 1. Parameters of simulated DFIG system are shown in Table 1. Control parameters of FOPID regulator are given in Table 2. The time of domain simulation is $20 \mathrm{~ms}$.

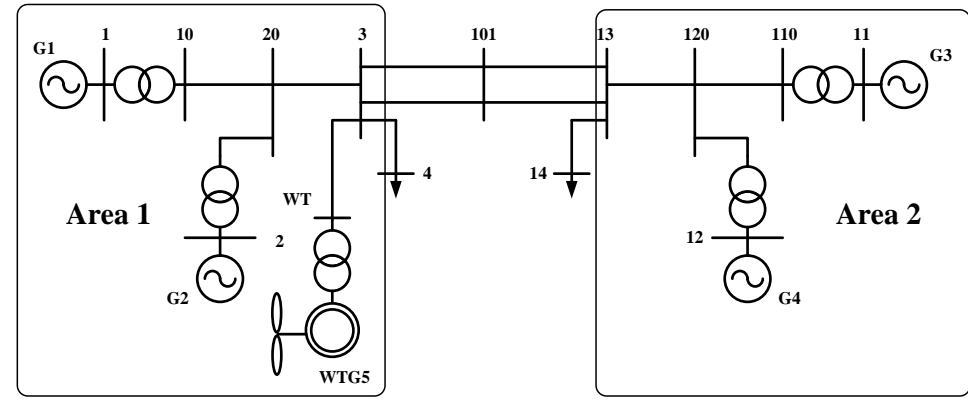

Figure 5. Four-Generator Two-Area Test System

Table 1. Parameters of DFIG System

\begin{tabular}{|l|l|}
\hline Parameters & Value \\
\hline Rated power & $1.5 \mathrm{MW}$ \\
\hline Line-to-line voltage & $575 \mathrm{~V}$ \\
\hline Stator frequency & $60 \mathrm{~Hz}$ \\
\hline$R_{s}$ & $0.00706 \mathrm{p} . \mathrm{u}$. \\
\hline$R_{r}$ & $0.005 \mathrm{p} . \mathrm{u}$. \\
\hline$L_{s}$ & $0.171 \mathrm{p} . \mathrm{u}$. \\
\hline$L_{r}$ & $0.156 \mathrm{p} . \mathrm{u}$. \\
\hline$L_{m}$ & $2.9 \mathrm{p} . \mathrm{u}$. \\
\hline Pole pairs & 2 \\
\hline Inertia constant & $5.04 \mathrm{~s}$ \\
\hline
\end{tabular}


In order to verify effectiveness of proposed DFIG-FOPID, the following a case are considered:

Approximately 400MW power flows from Area 1 to Area 2. The inter-area mode, which is (G1 G2) and (G3 G4), is the important mode. It is excited by disturbances, which is a 3 phase fault at bus 101 for $200 \mathrm{~ms}$.

\section{Table 2. Control Parameters of FOPID Regulator}

\begin{tabular}{|l|l|}
\hline Parameters & Value \\
\hline$k_{i}$ & -40 \\
\hline$k_{p}$ & -40 \\
\hline$k_{d}$ & -40 \\
\hline$v_{d}$ & 0.5 \\
\hline$v_{i}$ & -0.5 \\
\hline
\end{tabular}

(1)Extraction of Oscillation Mode:As shown in Table 3, the oscillation mode results can be obtained by SSI method. We can see that the inter-area oscillation modes are identified by SSI. In Figure 6, a identified critical mode shape is shown.

In contrast with SSI, active power signal of tie-line can be used to get the important mode by Prony. The results obtained by Prony are shown in Table 4. Compared with Prony, we can seen that the identification results obtained by SSI are nearly same. At the same time, compared with Prony, there are also other methods such as Hilbert Huang Transform [28], Wavelet transform [29], Spectral analysis [30], et al. SSI has the high robustness.

Table 3. Identification Results Acquired with SSI Algorithm

\begin{tabular}{|c|c|c|c|c|}
\hline \multirow{2}{*}{ Case } & \multicolumn{2}{|c|}{ Inter-area oscillation mode } & $\begin{array}{l}\text { Oscillation } \\
\text { generator } \\
\text { cluster(area) }\end{array}$ & $\begin{array}{l}\text { Critical } \\
\text { mode }\end{array}$ \\
\hline \multirow{2}{*}{$a$} & Frequency (Hz) & Damping (\%) & 1 \\
\hline
\end{tabular}

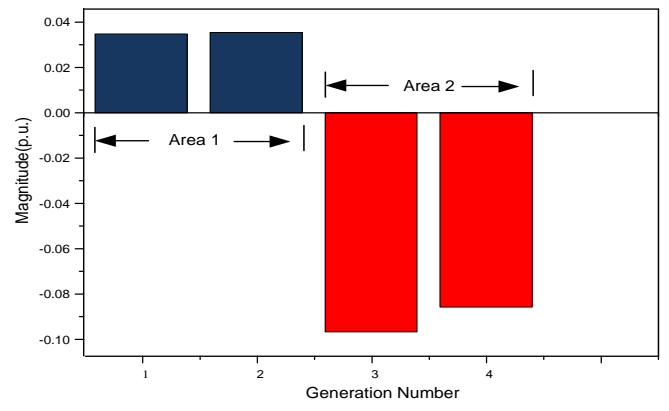

Figure 6. Theoretical Mode Shape of the Important Mode under Case a

(2)Effectiveness of Adaptive WADC Scheme: As shown in Table 3, a insufficient damping inter-area oscillation mode in disturbance was identified. As shown in Figure 6, 
the corresponding oscillation generator clusters were identified. The WADCs are designed on WAMS data, in order to suppress the insufficient damping inter-area oscillation modes in disturbance.

The effectiveness of inter-area oscillation damping control in different case with no WADC, and WADC-FOPID for DFIG was verified in Figures 7-8.

Table 4. Identification Results Obtained by Prony Method

\begin{tabular}{|l|l|l|l|}
\hline \multirow{3}{*}{ Case } & \multirow{3}{*}{ Input } & \multicolumn{2}{|l|}{ Critical mode } \\
\cline { 3 - 4 } & & Frequency $(\mathrm{Hz})$ & Damping $(\%)$ \\
\hline \multirow{4}{*}{$a 1$} & $w_{G 1}$ & 0.73 & 2.5 \\
\cline { 2 - 4 } & $w_{G 2}$ & 0.73 & 2.8 \\
\cline { 2 - 4 } & $w_{G 3}$ & 0.7 & 0.91 \\
\cline { 2 - 4 } & $w_{G 4}$ & 0.67 & 1.3 \\
\cline { 2 - 4 } & $P_{3 \sim 13 a}$ & 0.71 & -0.84 \\
\hline
\end{tabular}

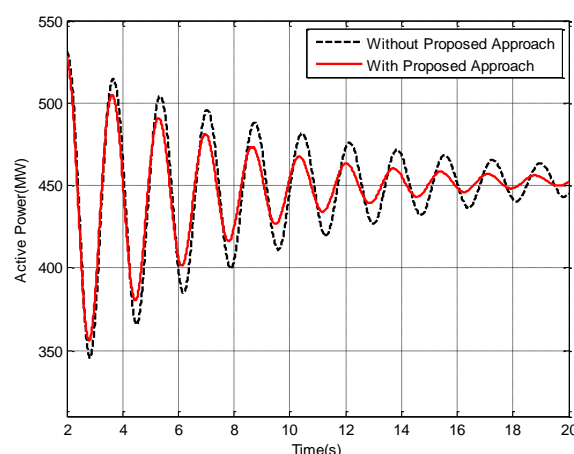

(a)Active Power for Tie-line 3-13

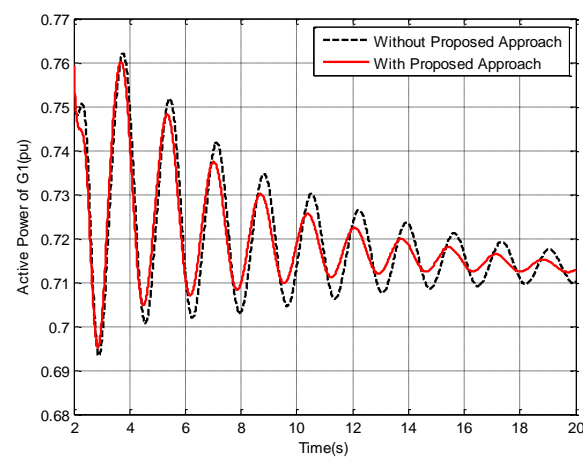

(c) Active Power for G1

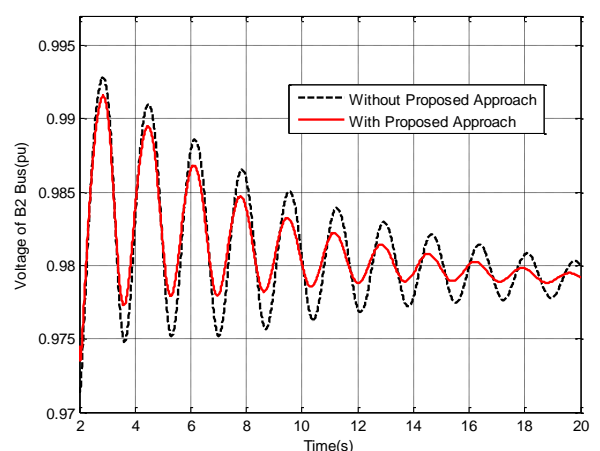

(b) Voltage for Bus 2

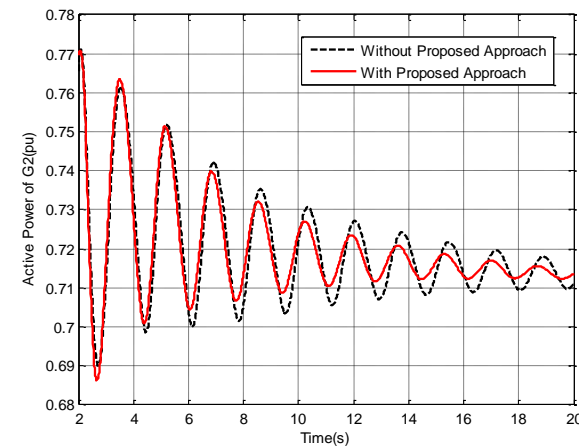

(d) Active Power for G2

Figure 7. The Control Effect of Case 1 under Different Control Schemes

Selected line flow for cases with no WADC, and WADC-FOPID for DFIG are shown in Figure 7. As to poor damping inter-area oscillation modes, if only LPSSs were installed, the oscillation of system will be settle down in some time. But oscillations are suppressed quickly as shown in Figure 7 for case based on proposed DFIG-WADC. At the same time, voltage of Bus 2, active power of G1-G2 and rotor speed difference of $w_{13}$ is verified under different control scheme.

The effectiveness of the WADC is weaken without FOPID. The proposed DFIGFOPID scheme works very well. As shown in Figure 8(b), electromagnetic torque 
changes of DFIG reduces under the proposed controller when power grid fault. The impact to mechanical stress of rotor system of wind turbine has be effectively reduced.

CASE 2:As shown in Figure 9, the 7-generator 4-area system was used for evaluating the performance of the proposed WADC scheme based on DFIG-FOPID. The simulation of multi-area system is carried out by constructed two 4-generator 2-area system that one generator is removed. This system contains 4 areas, Area 1 (G1-G2), Area 2 (G3-G4), Area 3 (G5) and Area 4 (G6-G7). LPSSs are equipped in G1,G3. A 30*1.5MW DFIG wind farm is accessed to power system in AREA 1. Control parameters of FOPID regulator are given in Table 5.

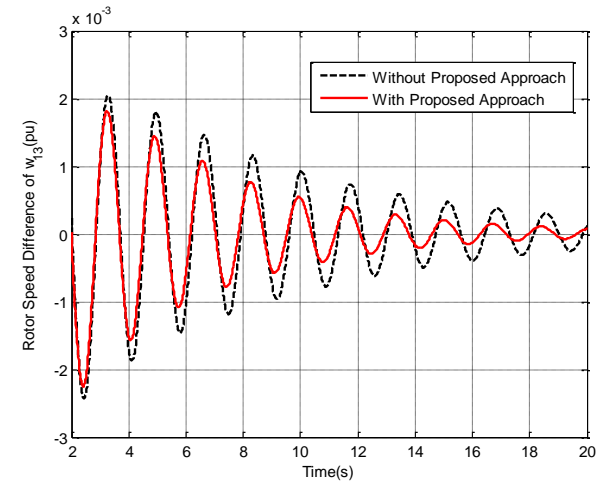

(a) Rotor Speed Difference of w13

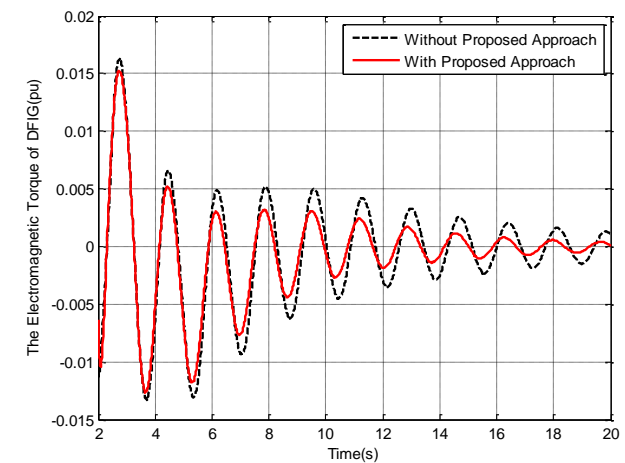

(b) The Electromagnetic Torque of DFIG

Figure 8. The Control Effect of Case 1 under Different Control Schemes

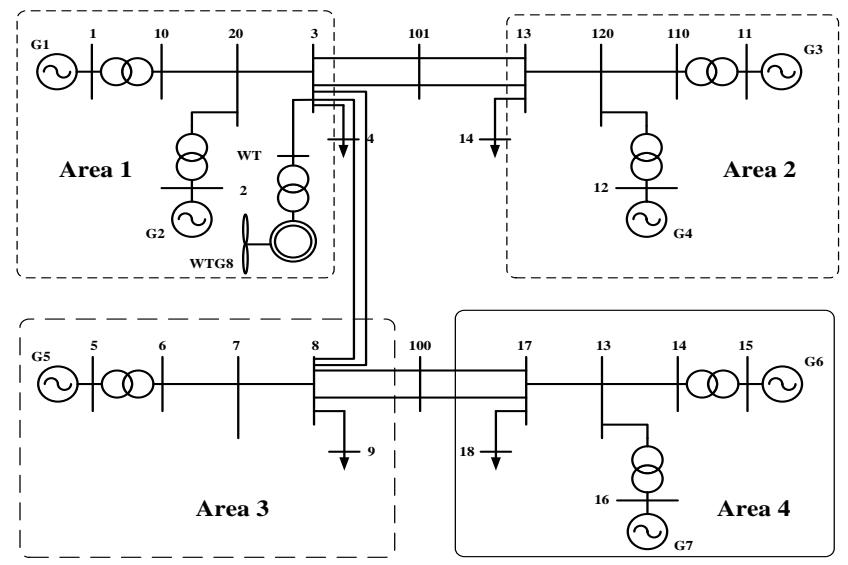

Figure 9. 7-generator 4-area Test System

\section{Table 5. Control Parameters of FOPID Regulator}

\begin{tabular}{|l|l|}
\hline Parameters & Value \\
\hline$k_{i}$ & -110 \\
\hline$k_{p}$ & -110 \\
\hline$k_{d}$ & -110 \\
\hline$v_{d}$ & 0.5 \\
\hline$v_{i}$ & -0.5 \\
\hline
\end{tabular}

In order to verify effectiveness of proposed WADC scheme, the following case is considered: 
Approximately $300 \mathrm{MW}$ power flows from Area 1 to Area 2 . The inter-area mode which is the important oscillation mode is excited by the case: 3-phase fault at bus 101 for $100 \mathrm{~ms}$.

(1)Oscillation Mode Extraction: The results obtained by SSI are shown in Table 6. We can seen that SSI can identify oscillation modes. One identified important inter-area oscillation mode shape is shown in Figure 10.

Table 6. Identification Results Acquired with SSI Algorithm

\begin{tabular}{|c|c|c|c|c|c|}
\hline Case & \multicolumn{3}{|c|}{ Inter-area oscillation mode } & \multirow{2}{*}{$\begin{array}{l}\text { Oscillation } \\
\text { generator } \\
\text { cluster(area) }\end{array}$} & \multirow{2}{*}{ Critical mode } \\
\hline$a$ & No. & Frequency $(\mathrm{Hz})$ & Damping $(\%)$ & & \\
\hline & 1 & 0.6636 & 0.5125 & $\{2\} \operatorname{vs}\{3\}$ & 1 \\
\hline
\end{tabular}

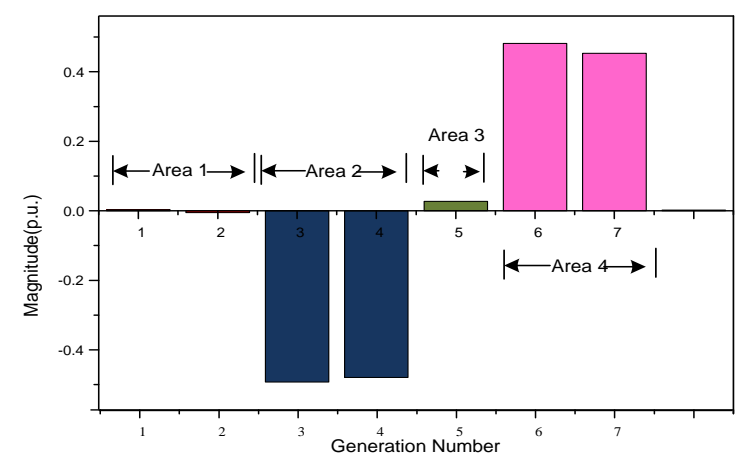

Figure 10. Theoretical Mode Shape of the Critical Mode under Case a

(2)Effectiveness of Adaptive WADC Scheme: One important poor damp inter-area oscillation mode was identified in Table 6. The ideal inter-area oscillation modes are shown in Figure 10. WADC was constructed accordingly to input extracted from WAMS data, in order to suppress important insufficient damping inter-area oscillation modes in disturbance case.

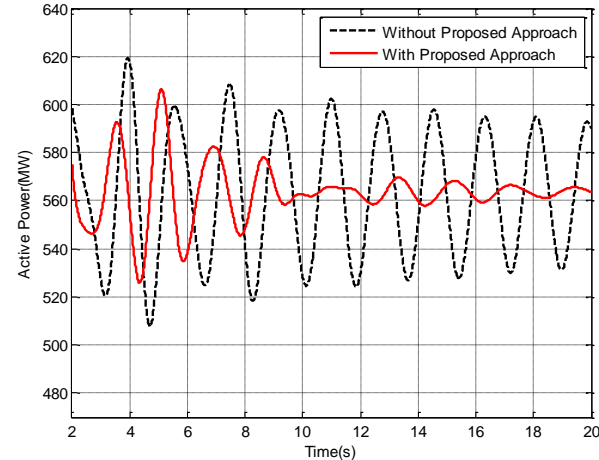

(a) Active Power for Tie-line 3-13

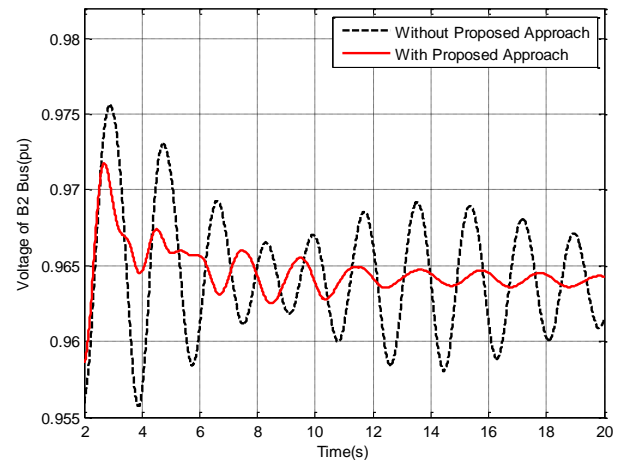

(b) Voltage for Bus 2

Figure 11. The Control Effect of Case 2 under Different Control Schemes

Figures 11-12 plot the selected line flow of different areas, voltage of Bus 2,and active power of G2 for cases with no WADC, and WADC-DFIG-FOPID. As to poor damp in important inter-area oscillation modes, if only LPSSs were installed, the system 
oscillation will be settle down in some time. But oscillations are suppressed quickly as shown in Figures 11-12 by proposed WADC.

The effectiveness of the WADC significantly weaken without DFIG-FOPID are demonstrated. The proposed DFIG-FOPID scheme works very well. As shown in Figure 12(b), electromagnetic torque changes of DFIG reduces under the proposed controller when power grid fault. The impact to mechanical stress of rotor system of wind turbine has be effectively reduced.

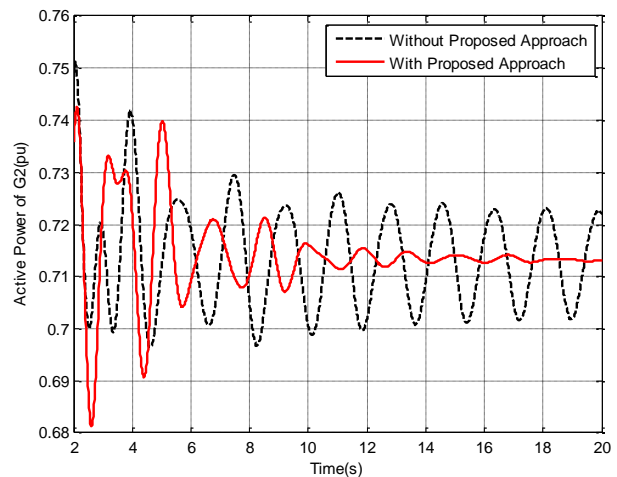

(a) Active Power for G2

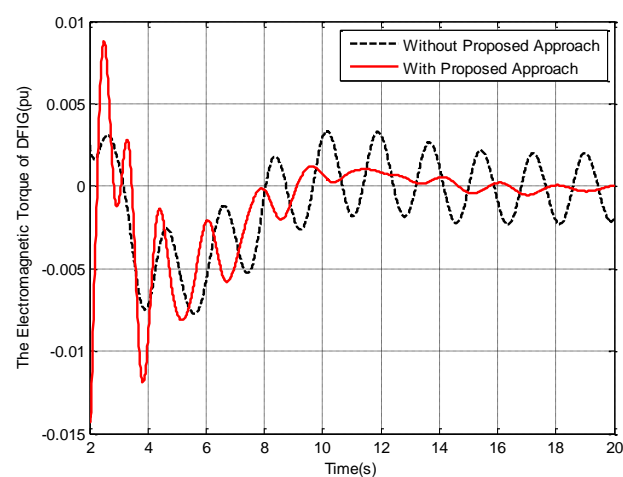

(b) The electromagnetic torque of DFIG

\section{Figure 12. The Control Effect of Case 1 under Different Control Schemes}

\section{Conclusion}

A adaptive WADC based on DFIG-FOPID is presented in this paper. Firstly, low frequency oscillation parameters are estimated using SSI, and then adaptive WADC is designed based on DFIG-FOPID. The simulation results show that: 1) In order to increase the adaptability of damping control, low-frequency oscillation of the interconnected power grid is detected by SSI, which can make sure whether there is power oscillation. At the same time it can identify the system state space mode and provide the basis for damping control; 2) Wide-area damping control strategy of DFIG is designed on the fractional order PID, it can provide damping for system, and effectively suppress interarea oscillation. It can improve the system control precision.3)This method has good dynamic characteristics under different case, and has the advantages of quick response, strong adaptability. The proposed method is simple to be designed, and easy to implement. It provides a new way for damping control of interconnected power system.

\section{Acknowledgments}

This work was supported by the National Natural Science Foundation of China (No.51377017) and the national key research and development plan (2016YFB0900100).

\section{References}

[1] P. Kundur, "Power system stability and control", New York: McGraw-Hill, (1994).

[2] S. Amin, S. Hossein, T. Navid, M. Y. Ghorban, "Robust coordinated control of damping controllers for improving of dynamic stability in multi-machine environment", International Journal of Automation and Control, vol.8,no.3,(2014), pp. 260-276.

[3] A. A. Hashmania, I. Erlich, "Mode selective damping of power system electromechanical oscillations for large power systems using supplementary remote signals ", International Journal of Electrical Power \& Energy Systems , vol.42,no.1,(2012), pp. 605-613.

[4] A. Jeevanandham, J. Sumathi, J. Mo, "Damping of inter-area oscillations in multimachine systems", International Journal of Automation and Control, vol.8, no.1, (2014), pp. 32-57.

[5] A. Prince, N. Senroy, R. Balasubramanian, "Targeted approach to apply masking signal-based empirical mode decomposition for mode identification from dynamic power system wide area 
measurement signal data”, IET Generation, Transmission \& Distribution, vol.5, no.10, (2011), pp.1025 1032.

[6] D.Y. Cai, P. Regulski, M. Osborne, V. Terzija, "Wide area inter-area oscillation monitoring using fast nonlinear estimation algorithm", IEEE Transactions on Smart Grid, vol.4, no.3, (2013), pp. 1721 1731.

[7] S.A. Gerardo, C. Virgilio, T. James, "Gain scheduling with classification trees for robust centralized control of PSSs", IEEE Transactions on Power Systems, vol.31, no.3, (2016), pp. 1933 - 1942.

[8] R. Shekha, L. Dhaval, K. N. Sisir, J. Tony, T. Praveen, "Estimation of low-frequency modes in power system using robust modified Prony", IET Generation, Transmission \& Distribution, vol.10, no.6, (2016), pp. $1401-1409$.

[9] V.K. Tayala , J.S. Latherb, "Reduced order Hळ TCSC controller \& PSO optimized fuzzy PSS design in mitigating small signal oscillations in a wide range", International Journal of Electrical Power \& Energy Systems, vol.68, (2015), pp. 123-131.

[10] C. Wang, Y. Shen, "Delay partitioning approach to robust stability analysis for uncertain stochastic systems with interval time-varying delay”, IET Control Theory \& Applications, vol.6, no.7, (2012), pp. $875-883$.

[11] Q. Quan, D. Yang, K.-Y. Cai, "Brief paper: Linear matrix inequality approach for stability analysis of linear neutral systems in a critical case", IET Control Theory \& Applications, vol.4, no.7, (2010), pp. $1290-1297$.

[12] M. Beza, M. Bongiorno, "An adaptive power oscillation damping controller by STATCOM with energy storage", IEEE Trans Power Syst, vol.30, no.1, (2015), pp. 484-493.

[13] P. Jiang, S. Feng, X. Wu, "Robust design method for power oscillation damping controller of STATCOM based on residue and TLS-ESPRIT", International Transactions on Electrical Energy Systems, vol.24, no.10, (2014),pp.1385-1400.

[14] B. Zhao, H. Li, M.Y. Wang, Y.J. Chen, S.Q. Liu, D. Yang, C. Yang, Y.G. Hu, Z. Chen, “An active power control strategy for a DFIG-based wind farm to depress the subsynchronous resonance of a power system", International Transactions on Electrical Energy Systems, vol.69, (2015), pp. 327-334.

[15] S. Mohit, J. A. Alicia, M. Eduard, V. Gevorgian, Y. Zhang, S. Santoso, "Interarea Oscillation Damping Controls for Wind Power Plants", IEEE Transactions on sustainable energy, vol.6, no.3, (2015), pp. 967975.

[16] M. Maghsoud, A. Farrokh, "Toward Wide-Area Oscillation Control Through Doubly-Fed Induction Generator Wind Farms", IEEE Transactions on Power Systems, vol.29, no.6, (2014), pp. 2985 - 2992.

[17] L. D. José, E. Carlos, U. Fernando B., O. Gomis, “ Input-output signal selection for damping of power system oscillations using wind power plants", International journal of Electrical Power and Energy Systems, vol.58, (2014), pp. 75-84.

[18] R.D. Fernández, R.J. Mantz, P.E. Battaiotto, "Linear and non-linear control of wind farms. Contribution to the grid stability", International journal of Hydrogen Energy, vol.35, no.11, (2010), pp. 6019-6024.

[19] S. Tossaporn, N. Issarachai, "Robust power oscillation damper design for DFIG-based wind turbine based on specified structure mixed H2/Ho control”, Renewable Energy, vol. 66, (2014), pp. 15-24.

[20] D. Sanjoy, C. S. Lalit, S. Nidul, "Automatic generation control using two degree of freedom fractional order PID controller", International journal of Electrical Power and Energy Systems, vol.58, (2014), pp. $120-129$.

[21] Y.G. Tang, M.Y. Cui, C.C. Hua, L.X. Li, Y.X. Yang, "Optimum design of fractional order $\mathrm{PI}^{\mathrm{k}} \mathrm{D}^{\mu}$ controller for AVR system using chaotic ant swarm”, Expert Systems with Applications, vol.39, (2012), pp. 6887-6896.

[22] A. T. Seyed, H. F. Masoud, F. A. Saber, "Fractional order PID controller design for LFC in electric power systems using imperialist competitive algorithm", Ain Shams Engineering Journal, vol.5,(2014), pp.121-135.

[23] S. Isabel, T. Jesus, J. A. Machado, "Application of Integer and Fractional Models in Electrochemical Systems", Mathematical Problems in Engineering, (2012), pp. 1-17.

[24] Y. Luo, T. Zhang, Lee B. J., "Fractional-Order Proportional Derivative Controller Synthesis and Implementation for Hard-Disk-Drive Servo System", IEEE Transactions on control system technology, vol.22, no.1, (2014), pp. 281-289.

[25] I. Pan, S. Das, "Intelligent Fractional Order Systems and Control” ,Berlin,Germany: Springer-Verlag, (2013), pp.15-65.

[26] S. A. Nezam Sarmadi ; V. Venkatasubramanian, "Electromechanical Mode Estimation Using Recursive Adaptive Stochastic Subspace Identification," IEEE Transactions on Power Systems,vol. 29, no.1, (2014), pp. 349 - 358.

[27] T. Jiang, H.Y. Yuan , H.J. Jia, N. Zhou, F.X. Li, "Stochastic subspace identification-based approach for tracking inter-area oscillatory modes in bulk power system utilising synchrophasor measurements," IET Generation, Transmission \& Distribution, vol.9, no.15, (2015), pp. 2409 - 2418.

[28] A. T. Ranjit, "Estimation of Teager energy using the Hilbert-Huang transform", IET Signal Processing, vol.9, no.1, (2015), pp. 82 - 87. 
[29] S. Avdakovica, A. Nuhanovicb and M. Kusljugic, "Wavelet transform applications in power system dynamics," Electric Power Systems Research, vol.178, no.2, (2012), pp. 237-245.

[30] S. Shahrampour, V. M. Preciado, "Topology identification of directed dynamical networks via power spectral analysis," IEEE Transactions on Automatic Control, vol.60, no.8, (2015), pp. 2260 - 2265.

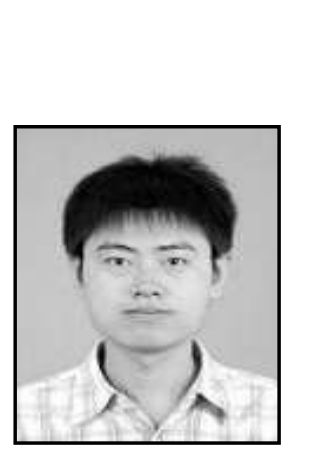

\section{Authors}

Cheng Liu, he received MSc degree in Electrical Engineering from the Northeast Dianli University, Jilin, China in 2012. He is currently a Ph.D. student at North China Electric Power University, Beijing, China. His research interests are in stability and control of power system, wind power generation, damping control. 
International Journal of Control and Automation Vol.10, No.7 (2017) 